\title{
Evaluation Model for Hospital Service Quality
}

\author{
Jin Yang ${ }^{1,2}$ \\ ${ }^{1}$ School of Management and Economics \\ University of Electronic Science and Technology of \\ China, Chengdu 611731, China \\ ${ }^{2}$ Affiliated Hospital of Chengdu University, Chengdu \\ 610081, China \\ dr.jinyang@163.com
}

\section{Xu Chen*}

School of Management and Economics

University of Electronic Science and Technology of

China, Chengdu 611731, China

xchenxchen@263.net

* Corresponding author

\begin{abstract}
The level of hospital service quality is playing an increasingly important role in hospital competition in China. To evaluate that quality, this paper deeply studied the present service status and the service quality evaluation in China's hospital from the angle of patients, and innovatively proposed an evaluation model in accordance with China's medical industry characteristics based on the classical SERVQUAL model. This model consists of three dimensions' indicators, and describes the general situations and various influence factors of hospital service quality from tangibles, security, responsiveness, reliability, credibility. This paper provides an overall comprehension and scientific basis for enhancing hospital service quality.
\end{abstract}

Keywords-Hospital Service; Service Quality; Evaluation Model; Quality Indicators; Patients'Perception

\section{INTRODUCTION}

With people's material life improving continuously, the extent of publics' concerns to their own health is enhanced on an unprecedented scale. Medical and health become the hot topics in the people's attention. They have increasing demands for the healthcare industry, besides the basic demands, like higher medical technology, their concerns for medical services are stronger and stronger. Especially in recent years, great importance to hospital service causes that the medical institutions competition is gradually converted from medical technology level to the medical service quality. The quality has become the first element in medical market competition.

Quality level is related to the patient's safety and health, and concerning hospital service can affect hospital reputation and benefit, that is a necessary condition for the survival of medical institutions. For the public, hospital service has become a key element to choose after medical technology. While for the hospital, improving service can not only ease the contradictions between doctor-patient relationships, but also enhance core competitiveness of hospital.

However, due to the long-term market development, most hospitals in China focus on economic benefit but

\author{
Huan Yang \\ School of Management and Economics \\ University of Electronic Science and Technology of \\ China \\ Chengdu 611731, China \\ yanghuanmee@gmail.com
}

often ignore the services. First, long-term policy supportive medical institutions are poor management, outdated ideas and weaker cognition of service quality. Second, hospitals' researches on improving services are less with backward methods, which is adverse to improve service quality. The contractions, between hospital service importance and the difficulty and inefficiency to enhance service quality, seriously restrict the development of hospital services. To improve the hospital service quality, quality evaluation should be the key problems. Via mastering scientific quality evaluation methods, the hospital can control its service level rationally. And via implementing targeted policies, the hospital can improve its services and core competitiveness.

Through studying on hospital services, first, this paper provides a systematic, scientific, innovative theoretical reference for hospital service evaluation. Second, it provides feasible practice guidance. So, combining theory and practice, the evaluation with a set of effective system can not only facilitate emphasis on service quality and quality evaluation, but also improve the quality of hospital services.

\section{LITERATURE REVIEW}

Taking the American scholars as the principal group, scholars' studies on the quality involve various aspects, including building evaluation model and determining methods for specific indicators and so on.

As for model construction, there are mainly two groups. First, from the hospital perspectives, Donabetian (1966) ${ }^{[1]}$ suggested hospital service quality should be evaluated from personnel, technical and environmental dimensions. Starfield (1973) ${ }^{[2]}$ proposed a classic evaluation model for service quality, comprehensively considering structure, process and outcome. After that, scholars made the appropriate correction based on Stafield's model. Such as Victor Sower (2001) ${ }^{[3]}$ et al proposed a hospital key quality evaluation method, that is KQCAH, to evaluate the hospital service quality.

Second, from patients' perspectives, the most representative is Coddiangton and Moore (1987) ${ }^{[5]}$, who 
put forward five dimensions to universally cover the hospital service quality evaluation. Parasuraman, Zeithaml and Berry (1985) ${ }^{[6]}$ proposed SERVQUAL model based on their gap theory, which estimated service quality based on evaluators' subjective feeling. Anderson (1995) ${ }^{[7]}$ used it into the field of hospital service evaluation. Then PZB's SERVQUAL model becomes a classic model in that field. Some scholars also questioned this model and proposed other evaluation models based on it: Cronin and Taylor (1993) [8] introduced SERVPERF model namely 'performance perceived service quality measurement model'.

For indicators determination, Baki B and Peker I (2015) [9] used Fuzzy Analytic Hierarchy Process (FAHP) and Fuzzy TOPSIS (FTOPSIS) to rank the hospitals' services perceived according to service quality. Jinkyung Kim, Woosok Han (2012) [10] investigated the quality dimensions perceived by hospital workers with multivariate ordinary least squares regression analysis.

China's scholars mainly concentrated on the empirical methods or indicators modification. Shieh JI, Wu HH and Huang KK (2010) ${ }^{[11]}$ did a survey based on SERVQUAL model to confirm seven major criteria. Then evaluate the importance of criteria from hospital management to find the causal relations among these standards. Kong GL, Xu DL, Yang JB, et al (2015) ${ }^{[12]}$ used evidential reasoning approach to assess hospital quality combining evaluation indicators, expert opinion and patient perception. TsungHan Chang (2014) ${ }^{[13]}$ did empirical analysis with VIKOR method under uncertain and fuzzy environment.

Above all, scholars abroad mostly construct corresponding model to evaluate hospital service quality, yet domestic scholars either discuss model abroad or focus on empirical research. Building the own SERVQUAL evaluation system for medical service quality is still rare.

\section{SER VICE QUALITY EVALUATION MODEL}

This paper, based on SERVQUAL framework, innovatively presented an evaluation model for hospital service quality in line with the characteristics of China's medical industry and the influence factors of service quality. The three levels in the model are as follows.

The first class indicators, i.e. the overall conditions of hospital service quality, roughly grasp the pros and cons situation of hospital service quality from the macro, mainly solve 'whether the service quality is good or bad', and make the overall positioning of service quality and determine its location.

The second class indicators, via the analysis of factors affecting service quality, measure its quality by choosing corresponding dimensions from tangibles, security, responsiveness, reliability, credibility, mainly solve 'the level difference' among hospital service quality.

The third class indicators, via concrete elaboration of secondary indicators, mainly solve 'the level difference' among secondary indexes, comprehensively assess service quality by specific details and determine specific situations of its quality.

\section{INDICATORS ANALYSIS OF EVALUATION MODEL}

Indicators are basic dimensions of the evaluation model, are concrete projects to assess that quality. This section will respectively dismantle and analyze elements of three class indicators above, confirm the relationships and functions among various key indicators, and then make explanation for the the evaluation model.

\section{A. The first class indicators}

The indicators mainly investigate the pros and cons of hospital service quality. The key elements of the level are tangibles, security, responsiveness, reliability, credibility.

\section{B. The second class indicators}

These indicators measure the hospital service quality via choosing corresponding dimensions from tangibles, security, responsiveness, reliability, credibility. That is 'from which dimensions to evaluate'. There are eleven key elements constituting the level indicators: medical technology, service attitude, service specification, medical procedures, medical process, waiting time, hospital facilities, hospital catering, health environment, charging price and privacy protection, as shown in Figure 1.

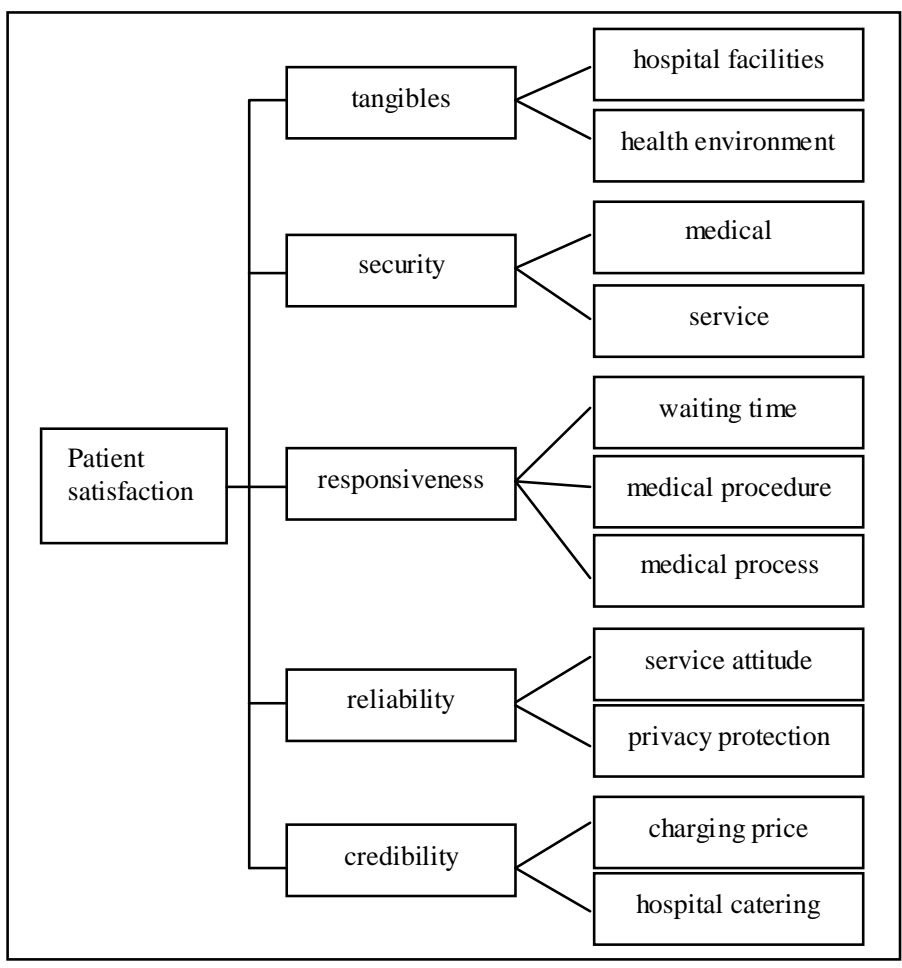

Figure 1. secondary indexes of hospital service quality evaluation model

\section{- Tangibles}

Tangibles refer to the objective carrier of services provided and actually experienced by patients. Tangibles include service personnel's appearance and physical evidence like facilities, equipment, publicity materials in the service scene. Here for hospital services, tangibles are hospital facilities and sanitary environment.

\section{- Security}

Security refers that patients feel safe and reliable and believe the service provider's commitments can be effectively implemented. Security generally covers providing safe, reliable services for patients. Here it includes two aspects: medical technology and service standards. 


\section{- Responsiveness}

Responsiveness refers to the response time of servicing patients and solving efficiency when patients pose a question. So responsiveness is that corporate service personnel are willing to provide timely and effective services to patients. Here hospital services will concern waiting time, service process and medical procedures.

$\bullet$

\section{Reliability}

Reliability refers to consistent performance, behavior, and value the commitment to the consumers. Here assess the reliability of hospital services in the two aspects from service attitude and privacy protection.

\section{Credibility}

The key of credibility is regarding customers' interest as the highest priority, hospital should bring consumers responsibility, trust and honest feelings. This paper covers charging price and hospital catering.

\section{The third class indicators}

The indicators are the specific elaboration of the secondary indicators, namely what specific problems should be began to evaluate, as shown in Table 1 .

TABLE I. THE THIRD CLASS INDICATORS OF HOSPITAL SERVICE QUALITY EVALUATION MODEL

\begin{tabular}{|c|c|}
\hline $\begin{array}{l}\text { Secondary } \\
\text { indicators }\end{array}$ & The third class indexes \\
\hline $\begin{array}{l}\text { Hospital } \\
\text { facilities }\end{array}$ & $\begin{array}{l}\text { Rest seats; convenient shopping; (water, toilet, } \\
\text { bathroom); (television, books); completeness; } \\
\text { comfort; safety. }\end{array}$ \\
\hline $\begin{array}{c}\text { Health } \\
\text { environment }\end{array}$ & $\begin{array}{l}\text { Personnel sanitation; public environment; ward } \\
\text { environment; booth; toilet; cleaning and quiet. }\end{array}$ \\
\hline $\begin{array}{c}\text { Medical } \\
\text { technology }\end{array}$ & Doctors' skills; nurses' skills; medical equipment. \\
\hline $\begin{array}{c}\text { Service } \\
\text { specification }\end{array}$ & $\begin{array}{l}\text { Medical guidance; process explanation; choice } \\
\text { respect; privacy protection; ward round } \\
\text { conditions; medical ethics. }\end{array}$ \\
\hline Waiting time & $\begin{array}{l}\text { Registering; outpatient service; inspection; taking } \\
\text { medicine; surgery; response. }\end{array}$ \\
\hline $\begin{array}{c}\text { Medical } \\
\text { process }\end{array}$ & $\begin{array}{l}\text { Signs; distance; order; complaints; medical } \\
\text { procedures. }\end{array}$ \\
\hline $\begin{array}{c}\text { Medical } \\
\text { procedure }\end{array}$ & $\begin{array}{l}\text { Procedures like registration, fees and getting } \\
\text { medicine; inspection procedures; admission } \\
\text { procedures; discharge formalities. }\end{array}$ \\
\hline $\begin{array}{l}\text { Service } \\
\text { attitude }\end{array}$ & $\begin{array}{l}\text { (Leading examining, registering, charging } \\
\text { personnel); doctors; nurses; activeness and } \\
\text { seriousness; problem solving; willing to listen. }\end{array}$ \\
\hline $\begin{array}{c}\text { Privacy } \\
\text { protection }\end{array}$ & $\begin{array}{l}\text { No telling others; no selling to the profit } \\
\text { organizations; the right to know the treatment. }\end{array}$ \\
\hline $\begin{array}{c}\text { Charging } \\
\text { price }\end{array}$ & $\begin{array}{l}\text { Opening and transparent; detail and clear; } \\
\text { consistency; reply. }\end{array}$ \\
\hline $\begin{array}{l}\text { Hospital } \\
\text { catering }\end{array}$ & $\begin{array}{l}\text { Types of food; taste of food; price of food; } \\
\text { convenience and speedy. }\end{array}$ \\
\hline
\end{tabular}

- Hospital facilities: medical environment should guarantee the ordinary needs of patients. Whether the facilities are complete will influence patients' life and entertainment to a certain extent. So, the hospital facilities will be refined to the seats, convenient shopping, toilet, water, television, books, completeness, comfort, safety.

- Health environment: it also affects the psychological and physical health of patients to a certain extent, including personnel health, public environment, ward environment, water room, bathroom, cleaning frequency and the degree of quiet.
- Medical technology: it should concrete various aspects of hospital medical technology. Its level mainly embodied in doctors' skills, nurses' skills and medical devices etc.

- Service specification: considering the service specification situations of related service, it is subdivided into medical guidance, process explanation, choice respect, privacy protection, ward round conditions, medical ethics.

- Waiting time: long waiting time easily makes patients feel irritable, meanwhile causes adverse effects for disease or illness. Waiting link in the treatment faced with the patients is the indicators: registration, outpatient service, checking, taking medicine, operation, the time that the doctor to ward and the nurse to ward.

- Medical process: it refers to a general term of a series of medical activities that the patient from into the hospital to the final out of the hospital. It's usually an important index influencing patient satisfaction, measured by signs (process, leading examining), distance, layout, order, complaint and so on.

- Medical procedure: when patients are in the hospital, the difficult degree to deal with various formalities will bring great influence on their evaluation of hospital service quality. Among them, it mainly includes registration, fees, taking medicine, checking, hospitalization and leaving hospital.

- Service attitude: patients in the hospital will face a lot of relevant staff, whose service attitude will determine the level of hospital service quality. It includes the leading examining, registration, charge personnel, doctors offering treatment, doctors offering check, nurse, initiative and seriously, solving problems, willing to listen.

- Privacy protection: patients to the hospital treatment, especially hospitalized patients, will coexist sorts of patients in ward. And some closely guard their illness. Whether the hospital staff can protect patients' privacy can affect their perception of hospital. It includes no telling others, no selling to profit institutions and the right to know treatment methods.

- Hospital catering: for ill patients, reasonable diet can take subsidiary function to treat injuries and can meet the nutritional needs of patients. Project team subdivided the hospital catering into types, price, taste of food and convenience.

- Charging price: dissatisfactory price will affect patients' intentions to the hospital next time. Charging price is summed up in reasonable price, detail and clearness, consistency, reply.

\section{CONCLUSIONS}

Based on the important influence element of the hospital core competitiveness, namely hospital service quality as the research object, this paper has an in-depth research about the current evaluation model construction and index selection for service quality. And we discover that the majority researches on evaluation at present mainly focus on demonstrating models abroad or empirical 
analysis. It lacks an overall analysis of China's medical industry and evaluation model construction of hospital service quality in the case of grasping the details. So based on the classical evaluation model SERVQUAL, this paper constructs an evaluation model and determines indicators in accordance with the actual situation, considering the development features and special circumstances of the country's hospital service. This paper separately has detailed analysis and selection about secondary indexes and third class indicators, and analyzes the problems to be measured in each level's indicators. Base on that, a systematic architecture of hospital service quality evaluation was formed, and ultimately provides a scientific basis to help enhance the quality of hospital services.

\section{ACKNOWLEDGMENT}

This research is partially supported by National Natural Science Foundation of China (No. 71272128, 71432003), Program for New Century Excellent Talents in University (No. NCET-12-0087) and Specialized Research Fund for the Doctoral Program of Higher Education (No. 20130185110006).

\section{REFERENCES}

[1] Donabedian A, "Evaluating the quality of medical care," The Milbank memorial fund quarterly, vol. 44, pp. 166-206, July. 1966, doi: $10.2307 / 3348969$.

[2] Starfield B, "Health services research: a working model" The New England journal of medicine, vol 289, pp. 132-136, 1973, 289(3): 132-136, doi: 10.1056/NEJM197307192890305.

[3] Victor Sower, Joann Duffy, William Kilbourne, "The Dimensions on Service Quality for Hospitals: Development and Use of the
KQCAH Scale," Health Management Review, vol 26, pp. 47-59, Spring 2001.

[4] Coddington D, Moore K, "Quality of care as a business strategy: how customers define quality and how to market it," Healthcare Forum, 1987.

[5] A. Parasuraman, Valarie A. Zeithaml and Leonard L. Berry, "A Conceptual Model of Service Quality and Its Implications for Future Research, " Journal of Marketing, vol 49, pp. 41-50, Autumn 1985, doi: 10.2307/1251430.

[6] Anderson E A, “ Measuring service quality at a university health clinic," International Journal of Health Care Quality Assurance, vol 8, pp. 32-37, 1995.

[7] J. J. Cronin, Jr. S. A, "Taylor. Measuring Service Quality: A Reexamination and Extension," Journal of Marketing, vol 56, pp. 55-68, 1992.

[8] Hiidenhovi H, Laippala P, Nojonen K, "Development of a patientorientated instrument to measure service quality in outpatient departments" Journal of Advanced Nursing, vol 34, pp. 696-705, June 2001, doi: 10.1046/j.1365-2648.2001.01799.x.

[9] Baki B, Peker I, “An Integrated Evaluation Model for Service Quality of Hospitals: A Case Study From Turkey" Journal of multiple-valued logic and soft computing, vol 24, pp. 453-474, 2015 .

[10] Jinkyung Kim, Woosok Han, "Improving Service Quality in Longterm Care Hospitals: National Evaluationg on Long-term Care Hospitals and Employees Perception of Quality Dimensions," Osong Public Health \& Research Perspective, vol 3, pp. 94-99, June 2012,doi: 10.1016/j.phrp.2012.04.005.

[11] Shieh JI, Wu HH, Huang KK, "A DEMATEL method in identifying key success factors of hospital service quality," KNOWLEDGE-BASED SYSTEMS, vol 23, pp. 277-282, April 2010, doi: 10.1016/j.knosys.2010.01.013.

[12] Kong GL, Xu DL, Yang JB, Ma XM, "Combined medical quality assessment using the evidential reasoning approach," Expert Systems with Applications, vol 42, pp. 5522-5530, August 2015, doi: 10.1016/j.eswa.2015.03.009.

[13] Tsung-Han Chang, "Fuzzy VIKOR method: A case study of the hospital service evaluation in Taiwan," Information Science, vol 271, pp. 196-212, July 2014, doi: 10.1016/j.ins.2014.02.118. 